\section{CHANGING PLAYFIELD OF 3S MOBILITY} has been an exciting journey that has undergone a highest transformation over the $3 \mathrm{~S}$ aspects took a back seat since, since the priority was transportation between two points. pation of the affiliated industries is an imperative. The affiliated industries include but are not limited to energy providers, media, insurance, financing, rental cars \& parking, aftermarket sales \& spares, emergency services \& legal fees towards accidents and recalls. The upcoming era of car sharing and autonomous vehicles will up the ante of the current $3 \mathrm{~S}$ foundational assumptions, development and its affiliated industries.

\section{NEW ECOSYSTEM}

Market analysis shows, millennials and young adults, along with urbanites, are gravitating towards a model of personal mobility that is based on pay-per-use rather than upfront purchase of a vehicle, which fundamentally challenges today's consumption model centred on personal vehicle ownership. This implies that a well-established ecosystem for over a century is transforming to result in the emer-
Safe, smart and sustainable (3S) mobility the years. In the nascent days, some of

For the $3 \mathrm{~S}$ mobility ecosystem, partici- gence of a new ecosystem of $3 \mathrm{~S}$ mobility.

The fast pace growth of car sharing business model has resulted in diminishing ownership of personal vehicles and is affecting the conventional OEM business models. The radical change to autonomous vehicles could be a complete re-set of current state. On the other hand, it is pulling-in other industries to create a larger bandwidth of players. The customer expectations are now shifting from OEM to service provider for enhanced safety.

For the digital traveller, connectivity and smarts of the vehicle are again a natural expectation from the service provider. In turn, the liability is shifting from a consumer to car sharing provider and from the provider to OEM, instead of the conventional OEM-consumer model. As such, the sustainability aspect of the businesses will have a big play between OEMs and service providers.

On the sustainability front, interestingly some new industry players are encouraging use of a personal vehicle for vehicle sharing, while the owners are occupied with their day jobs rather than having the vehicle in parking space. This generates revenue for the owner and helps livelihood for a driver without having to buy a vehicle. On a similar note, another revenue stream for an $\mathrm{EV}$ owner is through re-feeding into the grid and

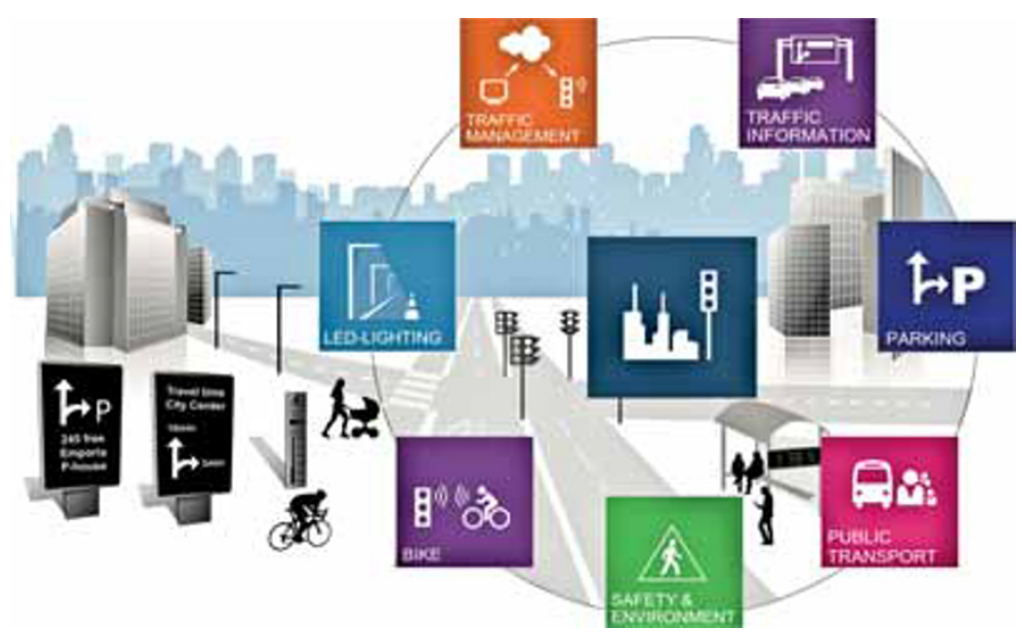

getting paid by energy providers.

The advent of autonomous vehicles will bring in a radical change in industry business $3 \mathrm{~S}$ models. This new ecosystem is being projected with lesser accidents, lesser travel cost per mile, rare traffic jams, drop in energy prices due to lower vehicles, disappearance of parking structures, increase in fleet sizes, lesser traffic infringement issues and several such positives.

As for smarts, the digital travellers' connectivity and impatience to get information and entertainment instantly will continue to push the envelope of OEMs and their vendor partners for better development.

\section{CHANGING DYNAMICS}

The projections show car-sharing reduces cost by $40 \%$ per mile, the driverless car reduces cost by $50 \%$ and the fully autonomous multi-modal system brings down cost by $70 \%$. These will certainly change the $3 \mathrm{~S}$ dynamics of the market depending on regulations and norms, and consumer demand in different regions of the world. Emissions are projected to reduce by more than $50 \%$, when these transitions have settled.

The fact of the matter is that $3 \mathrm{~S}$ research, development and feature implementations will dynamically change to synchronise with over-arching utility patterns and markets. Each organisation in this new ecosystem will have to determine where to play and how to win. Eventually, the market place, in its relentless quest for higher value at lower cost, will determine the players in the playfield that can sustain their existence to meet customer aspirations.

frr Read this article on www.autotechreview.com 